\title{
MILITANTISMO FILOSÓFICO Y ESPIRITUALIDAD POLÍTICA EN FOUCAULT
}

\author{
JAVIER DE LA HIGUERA \\ Universidad de Granada
}

\begin{abstract}
RESUMEN: En los últimos cursos que impartió en el Collège de France, entre 1980 y 1984, Michel Foucault dio un protagonismo creciente en sus investigaciones al cinismo antiguo. Su estudio histórico de la ética antigua, orientado primero hacia la experiencia moral de los placeres, y luego al tema del cuidado de sí y de las prácticas ascéticas a través de las cuales se constituye la subjetividad en el marco de una estética de la existencia, termina con el ejemplo de los cínicos a causa del fallecimiento de Foucault en junio de 1984. No obstante, los cínicos parecen representar al final de esos análisis un momento privilegiado, en cierto modo una culminación. El presente artículo pretende indagar en las razones de ese privilegio sobre la hipótesis de que, en los cínicos, Foucault encuentra respuesta al problema del aspecto voluntario de las resistencias al poder.
\end{abstract}

PALABRAS CLAVE: cinismo antiguo; heroísmo filosófico; espiritualidad; revolución iraní; resistencias.

\section{Philosophical Militantism and Political Spirituality in Foucault}

ABSTRACT: In the last courses he taught at the Collège de France, between 1980 and 1984, Michel Foucault gave increasing prominence to ancient cynicism in his research. His historical study of ancient ethics, oriented first towards the moral experience of pleasures, and then towards the theme of selfcare and ascetic practices within the framework of an aesthetic of existence, ends with the example of the cynics following Foucault's death in June 1984. Nevertheless, the cynics seem to represent at the end of these analyses a privileged moment, in a way a culmination. This article seeks to explore the reasons for this privilege over the hypothesis that, in cynics, Foucault finds an answer to the problem of the voluntary aspect of resistances to power.

KEY WORDS: ancient cynicism; philosophical heroism; spirituality; iranian revolution; resistances.

En la progresión temática observada en los cuatro últimos cursos de Foucault en el Collège de France -ética sexual antigua, cultura de sí, parresía éticofilosófica, cinismo- ${ }^{1}$, el cinismo pasa de ser un asunto circunstancial a ser el tema principal, al que el último curso dedica más de la mitad de las lecciones:

1 Los cuatro últimos cursos que Foucault imparte en el Collège de France son: Subjectivité et vérité. Cours au Collège de France. 1980-1981, Gallimard/Seuil, Paris 2014; L'Herméneutique du sujet. Cours au Collège de France. 1981-1982, Gallimard/Seuil, Paris 2014, 2001; Le gouvernement de soi et des autres. Cours au Collège de France. 1982-1983, Gallimard/ Seuil, Paris 2008; y Le courage de la vérité. Cours au Collège de France. 1984, Gallimard/Seuil, Paris 2009. 
el cinismo considerado como «la forma más típica de la filosofía antigua» ${ }^{2}$, «el primer ejemplo» de la idea de filosofía como arte de existencia ${ }^{3}$, o incluso «el núcleo universal de la filosofía ${ }^{4}$, al que Foucault llega a conceder un alcance «transhistórico» que atraviesa de manera «recurrente» toda la historia occiden$\mathrm{tal}^{5}$. Las razones de esta centralidad del cinismo en el ultimísimo Foucault no son evidentes y, al contrario, parece introducir en las investigaciones históricas de Foucault un elemento extraño que fácilmente da la impresión de un «salto»o «desconexión» difícil de explicar ${ }^{6}$.

\section{LA FIGURA DEL CÍNICO EN LA DESCRIPCIÓN DE LA ÉTICA ANTIGUA}

El cinismo parece comenzar siendo para Foucault simplemente el ejemplo de una de las escuelas filosóficas de la antigüedad, junto al estoicismo y el epicureísmo, estudiadas desde el punto de vista de su ética sexual y en relación con el surgimiento de la ética cristiana de la carne. Es caracterizado, sin embargo, por representar de un modo especialmente puro la vida o profesión filosófica, aunque el curso de 1980-1981, Subjectivité et vérité, presente este rasgo sólo en función del análisis histórico de la institución matrimonial. Veremos después cómo la atención al modo de vida filosófico se convierte más tarde en esencial. En ese lugar, el cinismo es tratado en relación con el problema de si el filósofo debe contraer matrimonio. El cínico es presentado como «el militante filósofo», con una expresión reiterada por Foucault también en otros lugares, sobre todo en el último curso en el Collège de France, tres años después ${ }^{7}$. El cínico es «alguien que vive cínicamente», "que es - repitiendo las palabras de Epicteto- sin ciudad, sin vestido, sin casa, sin mujer, sin hijos, sin patria ${ }^{8}$. Los cínicos son «filósofos completamente ascetas»" ${ }^{9}$, dedicados sólo a la filosofía. A diferencia del hombre ordinario, «que vive en el mundo", el cínico toma distancia crítica con respecto al estado actual de éste, lo cual le permite modificarlo, aunque le impide participar en él, por ejemplo, contrayendo matrimonio ${ }^{10}$.

2 En particular, la que se encuentra en el conocido retrato del cínico que hace Epicteto, al cual Foucault recurre en varias ocasiones. Ver Le gouvernement de soi et des autres, p. 318. [En adelante, las obras y títulos citados sin autor son de Foucault].

3 Le courage de la vérité, p. 118.

4 Ibíd., p. 187.

5 Ver Ibid., pp. 161 y 218.

6 Como ha visto J. Revel en «Promenades, petits excursus et régimes d'historicité», en: Lorenzini, D., Revel, A. y Sforzini, A. (eds.), Michel Foucault. Éthique et vérité (1980-1984), Vrin, Paris 2013, pp. 161-175.

7 Ver: Le courage de la vérité, pp. 261-262; L’Herméneutique du sujet, p. 134.

8 Subjectivité et vérité, p. 117.

9 Ibíd., p. 162.

10 «...el filósofo, por oposición al hombre público, es aquél para quien el mundo actual todo entero no es más que una circunstancia. Mientras que el hombre ordinario es alguien que vive en el mundo (...), por el contrario, el filósofo es aquél para quien la catástasis es una 
En L'Herméneutique du sujet, el curso del año 1981-1982, el cinismo es incluido en un modelo general de «ascética estoico-cínica» centrado en el principio del cuidado de sí (epimeleia heautou), que se contrapone al modelo del Alcibíades platónico, basado en el principio del conocimiento de sí (gnôthi seauton $)^{11}$. En el análisis de la evolución de la «cultura de sí» en los dos primeros siglos de nuestra era, la figura del cínico va a aparecer allí, sin embargo, en su singularidad, al tratar el proceso de desprofesionalización filosófica que sufre la práctica ascética cuando se convierte en una práctica social que rebasa la institución filosófica. En la lección del 27 de enero de 1982 (primera hora), se estudia el papel del filósofo como "maestro de subjetivación», "operador» en los individuos del paso de la stultitia a la sapientia, más que una simple educación, una transformación en el modo de ser de los sujetos ${ }^{12}$. Esta idea, según Foucault, está presente en todas las escuelas filosóficas: en los epicúreos, en los estoicos, pero especialmente en el ejemplo del rétor convertido a filósofo cínico, Dión de Prusia — con quien «vamos al límite», afirma Foucault: una imagen ésta, de "paso al límite», que va a ser central para Foucault más tarde a la hora de entender la peculiaridad del cinismo- - Lo que vendría a afirmar Dión es la idea de que el filósofo tiene la responsabilidad de la existencia entera de los individuos, a él hay que preguntarle acerca del modo en que uno debe conducirse y del modo en que se debe conducir a otros; el filósofo o el cínico, por tanto, como encrucijada del gobierno de sí y del gobierno de los otros: «El filósofo se presenta entonces, ruidosamente, como siendo el único capaz de gobernar a los hombres, de gobernar a aquellos que gobiernan a los hombres y de constituir así una práctica general del gobierno en todos los grados posibles: gobierno de sí, gobierno de los otros ${ }^{13}$. El análisis histórico realizado por Foucault en esta ocasión acerca de las diferentes formas de institucionalización de la filosofía helénica y romana va a presentar ese caso límite, que es el cinismo, como un momento excepcional, más bien contrario al signo de un proceso que culmina con el «consejero de existencia» romano, en el que la figura del filósofo alcanzará la mayor importancia pero también a costa de la propia profesión filosófica, disuelta en «el modo de ser cotidiano» con la consiguiente pérdida de «su función singular, irreductible, exterior a la vida cotidiana», tal como era encarnada por el cínico ${ }^{14}$.

En la segunda hora de la misma lección de 27 de enero, Foucault propone una interpretación del retrato de Éufrates que aparece en las Cartas de Plinio.

\footnotetext{
perístasis, para quien el mundo actual es una circunstancia. Y a causa de esta circunstancia, retoma de alguna forma por su cuenta esta circunstancia en relación con la cual se sitúa como crítico, como enunciador de la verdad, como mensajero de los dioses, a causa de esto no debe casarse». (Ibíd., p. 119). En la página siguiente: «esta idea de una catástasis como perístasis, de un estado del mundo como circunstancia de la que el filósofo debe distanciarse para modificarla...».

11 Véase L'Herméneutique du sujet, pp. 400-401.

12 Ver Ibid., pp. 130-131.

13 Ibíd., p. 131.

14 Ver Ibíd., pp. 138-139.
} 
Plinio habría dibujado a su maestro precisamente como lo opuesto de lo que se había considerado tradicionalmente «el filósofo de profesión», identificado con el personaje del cínico ${ }^{15}$. Y aunque sea como a contrario, el cínico es allí positivado nítidamente como «el punto extremo y, a los ojos de las gentes, el modelo negativo de la filosofía»: lo que es más evidente, en oposición al aspecto exterior pulcro y cuidado de Éufrates, se nos aparecen «esos filósofos de profesión con la barba descuidada, con vestimentas un poco asquerosas, que van por las calles»; en contraste con el lenguaje adornado y seductor del maestro de Plinio, el cínico es aquél que no hace concesiones a la retórica; frente al trato amable que Éufrates dispensa, la agresividad cínica, con la función de «desequilibrar de alguna forma, de perturbar al individuo en su modo de existencia, y de forzarlo, tirando de él, empujándolo a adoptar otro modo de existencia.» ${ }^{16}$; en contraste con la indistinción entre la vida filosófica y la vida política, en que se mueve Éufrates, el cínico representa «la retirada (retraite) de la filosofía en relación con la vida política» ${ }^{17}$.

\section{El CINISMO, DEL LADO DE LA «EDAD DESCRIPTORA»}

Bien remarcada en los anteriores pasajes de los cursos 1980-1982 la singularidad del cinismo, para Foucault no parece representar todavía más que un enclave preciso perteneciente a la historia de la cultura antigua de sí, fechado históricamente y perteneciente por ello a lo que podemos llamar, con expresión derridiana, la «edad descrita ${ }^{18}$. El paso del cinismo al lado de la «edad descriptora» comienza a producirse en el siguiente curso en el Collège de France, de 1982-1983, Le gouvernement de soi et des autres, donde se va a establecer el marco en el que el cinismo adquiere el protagonismo que tiene en las últimas investigaciones de Foucault y que es ya plenamente visible en el último curso, Le courage de la vérité. Ese protagonismo tendrá que ver, por tanto, con la conversión del cinismo en aquello desde lo cual se habla, siendo el nombre de un problema que es el de la actualidad y el de nosotros mismos, una clave importante para diagnosticar el presente e intervenir críticamente en él y, claro está, una referencia que arroja algo de luz sobre la propia posición teórica del último Foucault. El protagonismo del cinismo va a estar relacionado paradójicamente con una nueva revalorización por parte de Foucault del platonismo $-\mathrm{o}$ de un

15 Ver Ibíd., pp. 148-150.

16 Ibid., p. 148.

17 Ibid., p. 149.

18 Es la distinción que DERRIDA hace, precisamente en su lectura de la Histoire de la folie de Foucault, en "“Être juste avec Freud". L'histoire de la folie à l'âge du psychanalyse», en: Penser la folie. Essais sur Michel Foucault, Galilée, Paris 1992 (traducción española de C. de Peretti en Er. Revista de filosofía, 17/18, 1994-1995, pp. 105-158; ver p. 111). 
cierto Platón- y de la propia filosofía, en cuyo exterior, sin embargo, se había colocado Foucault desde los años sesenta ${ }^{19}$.

En el curso de 1982-1983, Foucault reinterpreta sus investigaciones anteriores a partir de la noción de parresía, que en el curso anterior aparecía sólo como una práctica ascética entre otras, como la lectura, la escucha o la escritura $^{20}$. En la parresía, Foucault ve ahora una «encrucijada» (carrefour) de los tres ejes de la experiencia: dominios de saber, tipos de normatividad y modos de relación consigo ${ }^{21}$. Es la parresía entendida como "foco de experiencia», es decir, como una práctica singular que, sin embargo, es capaz de contribuir a la apertura de un nuevo espacio histórico de experiencia - como parte de su «a priori histórico», por tanto-, lo que centra el interés de la investigación de Foucault en 1983. No olvidemos que, en general, la historia de la experiencia o del pensamiento es en Foucault una historia ontológica -o una ontología histórica-: el estudio de los modos en los que «el ser se constituye históricamente como experiencia ${ }^{22}$. Si la parresía es convertida en el tema principal de la investigación es porque adopta el papel de «hilo conductor» de la ontología histórica. Precisamente ese hilo será el que llevará a conceder al cinismo el papel privilegiado que finalmente tendrá. Sus claves, por tanto, no podrán ser sólo éticas sino también políticas y ontológicas.

\section{EL CINISMO Y «LO REAL DE LA FILOSOFÍA»}

Le gouvernement de soi et des autres opera un retroceso desde la época helenística y romana, estudiada en L'herméneutique du sujet, hasta la época clásica griega, en la que Foucault reconstruye el desplazamiento que la práctica de la parresía sufre desde su contexto político de surgimiento hasta su identificación con la práctica filosófica, convirtiéndose en «la acción filosófica propiamente dicha», algo que ocurre con Sócrates y Platón ${ }^{23}$. El significado de la parresía filosófica aparece en el análisis que Foucault realiza de la Carta VII de Platón. Pero lo que allí se encuentra es la escenificación de la «constitución» platónica de la filosofía, en el sentido de que en ese momento se produce la «inflexión» por la que la filosofía va a adquirir su concepto y lo que va a ser su «función general»,

19 He tratado de esa revalorización del platonismo en el último Foucault en «Un Foucault platonicien», en: Revue internationale de philosophie, 292/2, 2020, pp. 39-48.

20 Reinterpretación après coup muy característica de Foucault, una especie de «espiral hermenéutica», como señala F. Gros en la «Situation du cours» de L'herméneutique du sujet, p 497. Foucault mismo afirma: «...je le repasse après coup...» (Le gouvernement de soi et des autres, p. 8). Sobre la parresía en el curso de 1981-1982, véanse las pp. 348 ss.

21 Véase Le gouvernement de soi et des autres, pp. 44-45. Sobre esos tres ejes de la experiencia, véase asimismo: «Préface à l'Histoire de la sexualité» (1984), en: Dits et écrits, Gallimard, Paris 1994, vol. IV, p. 579; «Foucault» (1984), en: Ibíd., pp. 632-633;

22 L'usage des plaisirs, Gallimard, Paris 1984, p. 13.

23 Véase Le gouvernement de soi et des autres, p. 190. 
al menos en la filosofía antigua ${ }^{24}$. Es sabido que hasta Platón no hay un concepto filosófico de filosofía, una construcción filosófica de la propia práctica de la filosofía, y que ello se produce de manera polémica, frente a rivales como el fisiólogo, el sabio, o el sofista ${ }^{25}$. A diferencia de otros lugares platónicos tradicionales en los que podemos encontrar formulado el concepto de filosofía, como el Banquete - en el que Pierre Hadot apoya su análisis de la filosofía antigua como forma de vida, paralelo en gran medida al de Foucault $-{ }^{26}$, Foucault basa su interpretación fundamentalmente en esta Carta: probablemente, para él, la conceptualidad erótica que se deriva del Banquete, al menos en una primera lectura, era fácilmente asimilable al idealismo filosófico y, por el contrario, lo que en este lugar se está descubriendo en esa conceptualidad es para Foucault la forma general de existencia de la filosofía, su modo de pertenencia al mundo, descubrimiento de lo que este curso de 1982-1983 llama «lo real de la filosofía». La ocasión (kairos) del segundo viaje de Platón a Sicilia para aconsejar al tirano Dionisio obedece «a la obligación interna de la filosofía» de no ser simplemente logos sino además ergon, obra, tarea:

...preocupándose por la idea de que podría no ser nada más que discurso (logos), el filósofo (Platón) me parece plantear un problema, y un problema que es justamente, como les decía hace un momento, familiar y poco conocido. Cuando se preocupa por que pueda no ser más que logos, cuando quiere ser más que simple logos, tocar la tarea misma (el ergon), me parece que Platón despierta (soulève) una cuestión que podríamos llamar la de lo real de la filosofía ${ }^{27}$.

Se trata del punto en que la filosofía toca la realidad, en que ella misma es una realidad operante en el mundo. «Lo real de la filosofía» tiene que ver, por tanto, con su carácter político, con su relación con el poder: «La filosofía es la actividad que consiste en hablar verdadero, en practicar la veridicción, en relación con el poder ${ }^{28}$. La idea de una experiencia de la verdad que no tiene que ver con las condiciones meramente lógicas o gnoseológicas de la misma, sino

24 Ver Le gouvernement de soi et des autres, pp., 313, 315. En Le courage de la vérité (p. 33): «...quisiera mostrar hoy cómo ha podido constituirse, al menos en algunos de sus rasgos fundamentales, la filosofía occidental como forma de práctica del discurso verdadero». (subrayado mío).

25 Sobre ello puede verse: Vernant, J.-P., «Les origines de la philosophie», en: Delacampagne, C. et Maggiori, R., (eds.), Philosopher. Tome II, Fayard, Paris 1980, pp. 181-189; Deleuze, G., «Platon et le simulacre», en: Logique du sens, Minuit, Paris 1969, pp. 292-306.

26 Ver НАдот, P., «La définition du philosophe dans le Banquet de Platon», en: Qu'est-ce que la philosophie antique?, Gallimard, Paris 1995, pp. 70-87.

27 Le gouvernement de soi et des autres, p. 209.

28 Ibíd., p. 211. Foucault atribuye ahora a este momento filosófico fundador, que es el platónico, lo que en los años sesenta le había servido precisamente para criticar la filosofía desde una posición exterior a ella, que le proporciona lo que llama entonces «el modelo nietzscheano", capaz de afrontar la materialidad del conocimiento y de la verdad y su relación con el poder. Véase sobre ello el curso de 1970-1971, Leçons sur la volonté de savoir, Gallimard/Seuil, Paris 2011, pp. 148-149. 
con el plano existencial, con la manera en que la verdad afecta al «ser mismo del sujeto", había sido clave en el curso de 1981-1982 a la hora de definir lo que allí llamó Foucault «espiritualidad», y que constituye el tema principal de ese curso. Centrada en el principio del cuidado de sí, la espiritualidad designa una serie de prácticas ascéticas a través de las cuales el sujeto de transforma a sí mismo y se constituye en su ser: «....algo que realiza al sujeto mismo, que realiza el ser mismo del sujeto, o que lo transfigura ${ }^{29}$. En ese lugar, la espiritualidad era distinguida de la "filosofía», caracterizada por Foucault a partir del «momento cartesiano» como una filosofía separada de su propia materialidad y practicidad, de su inserción en el acontecer presente, equivalente también a lo que en otro contexto —el análisis del opúsculo kantiano Was ist Aufklärung?va a denominar «analítica de la verdad»: el estudio de las condiciones del conocimiento verdadero $^{30}$. Salta a la vista que la «filosofía» de la que trata en 1983 a partir del análisis de las Cartas de Platón, equivale a lo que en el curso del año anterior había llamado «espiritualidad». Si la espiritualidad era estudiada en el contexto de la cultura antigua de sí como una serie de prácticas de carácter ético —ethopoiéticas—, ahora la filosofía, «lo real de la filosofía», va a incorporar más netamente el aspecto político.

«Practicar la veridicción en relación con el poder» no es, sin embargo, decir la verdad de la política sino $a$ la política, y no es aplicar políticamente o prácticamente lo que se habría establecido antes en la teoría: «...es el hecho de que ella [la filosofía] se introduce, en su diferencia propia, en el interior del campo político $»^{31}$. Lo que representa, entonces, para Foucault lo esencial de la «constitución» platónica de la filosofía estaría en haber definido una práctica de la verdad inscrita en la realidad y en la historia, y que teniendo necesariamente una relación con la política, no coincidiría nunca con ella, manteniendo un principio de contestación, la capacidad para «decir no»: diferencia irreductible, alteridad o exterioridad de la filosofía con respecto al mundo político ${ }^{32}$. En «lo real de la filosofía» platónico estaría inscrita esa «retirada» de la filosofía en relación a la política que, veíamos antes, era atribuida en el curso anterior al cinismo. Cuando Le courage de la vérité presente al cinismo como «militantismo en el mundo, contra el mundo», no hará sino ahondar en esa idea de «lo real

29 L'Herméneutique du sujet, p. 18.

30 La contraposición entre espiritualidad y filosofía puede verse en L'Herméneutique $d u$ sujet, pp. 16-17. Sobre la analítica de la verdad, véase: «Leçon du 5 janvier 1983», Le gouvernement de soi et des autres (p. 22), lugar donde es contrapuesta a la «ontología de la actualidad».

$31 \quad$ Le gouvernement de soi et des autres, p. 211.

32 «relación necesaria» (Le courage de la vérité, p. 269); «relación perpetua de cara a cara, de contestación (contestation)» (Le gouvernement de soi et des autres, p. 313). La diferencia que, en este curso, establece entre la «exterioridad absoluta» cínica y la «intersección» platónica (ver pp. 264-265) es reinterpretada a mi juicio en el curso del año siguiente al profundizar en la estrategia cínica de "paso al límite»" de la filosofía platónica. En todo caso, no creo que sea abusivo atribuirle al Platón de la Carta VII, estudiado por Foucault, la idea de una «exterioridad relativa» de la filosofía con respecto a la política. 
de la filosofía» ${ }^{33}$. A pesar de la aparente oposición, a la que Foucault no deja de aludir, entre el cinismo y el platonismo ${ }^{34}$, esa oposición afecta más bien sólo a una línea de pensamiento, presente en Platón y que L'Herméneutique du sujet había encontrado en el diálogo Alcibiades, vinculada con la «metafísica del alma» y que, efectivamente, parece contrapuesta a la espiritualidad y a la «estética de la existencia» que ella desarrolla. Pero de Platón parte también —en los dos últimos cursos Foucault se apoya en el Laques así como en la Apología, en el Fedro y en las Cartas - esta otra línea de pensamiento que los cínicos van a personificar o encarnar.

\section{El aspecto Político de LA espiritualidad}

En el abandono del término «espiritualidad» en el curso del año 1982-1983 juegan diversos motivos, entre ellos, con seguridad, el deseo de desmarcarse del uso que hace P. Hadot de esa noción y de la de «ejercicios espirituales» —y del que era deudor L'Herméneutique du sujet— ${ }^{35}$ a causa de diferencias interpretativas que afectan, como el propio Hadot ha señalado, al escaso papel que Foucault concede en la espiritualidad antigua a la "conciencia cósmica» universalista, es decir, al conocimiento metafísico del cosmos, y al papel que otorga a Descartes en la drástica separación entre filosofía y espiritualidad ${ }^{36}$. Pero probablemente también explica ese cambio terminológico y, por tanto, la diferencia entre Hadot y Foucault, el carácter político que para Foucault tiene la espiritualidad, una vez que es introducida por él en el análisis de la gubernamentalidad y en el punto de vista de una ontología histórica y crítica ${ }^{37}$. L'Herméneutique du sujet se había limitado a indicar la importancia política de la espiritualidad y, por tanto, lo que hace de ella un enclave de nuestra situación

33 La expresión «militantisme dans le monde, contre le monde» se halla en Le courage de la vérité, pp. 262 y 279.

34 La diferencia llega a presentar a cinismo y platonismo como las «dos modalidades opuestas» a la hora de ligar cuidado de sí y coraje de la verdad, reinterpretando cada una a su manera la epimeleia y la parresía socráticas: la cínica, reduciendo al mínimo el papel de los conocimientos (mathemata) y la platónica, concediéndoles la mayor importancia, la primera vinculando el cuidado de sí a la fundación de la metafísica, la segunda, «en retirada en relación con la metafísica». Ver Le courage de la vérité, p. 310.

35 Ver Lorenzini, D., «Éthique et politique de nous-mêmes: à partir de Michel Foucault et Stanley Cavell», en: Lorenzini, D., Revel, A. y SForzini, A. (eds.), Michel Foucault. Éthique et vérité (1980-1984), pp. 239-254.

36 Véase НАдот, P., «Un dialogue interrompu avec Michel Foucault. Convergences et divergences», en: Exercices spirituels et philosophie Antique, Albin Michel, Paris 2002, pp. 305-311. Asimismo: "Reflexiones sobre la noción de "cultivo de sí mismo"», en: BaLIBaR, E., Deleuze, G. y otros, Michel Foucault, filósofo, Gedisa, Barcelona 1990, pp. 219-226.

37 Este aspecto lo ha visto con claridad J. CAVAGNIS en «Corbin, Hadot, Foucault: mise en dialogue de "Qu'est-ce que la philosophie islamique?", de Christian Jambet», en: Cahiers philosophiques, 2012/1, n 128 , pp. 111-125. 
actual, en relación con el problema de la resistencia al poder político: el punto de apoyo "primero y último» de la resistencia sólo puede estar, según Foucault, en la "relación de sí a sí», propia de la antigua espiritualidad ${ }^{38}$. Pero en ese momento el carácter político del problema aparece sólo de modo general y en términos de una extrapolación histórica del objeto de estudio a la problemática actual. El curso siguiente, Le gouvernement de soi et des autres, marca, como hemos visto ya, un cambio fundamental: la reinterpretación de la espiritualidad en términos de parresía filosófica y de «lo real de la filosofía» parece indicar que este aspecto político es para Foucault determinante de la propia espiritualidad. Prueba de ello también es que, aunque desde un ámbito de cuestiones muy diferente, el levantamiento iraní de 1978, Foucault había acuñado el concepto de «espiritualidad política» en varios artículos entre 1978 y 1980 -tendremos que preguntarnos después si hay alguna relación, y cuál puede ser, entre ambas nociones de espiritualidad-. En cualquier caso, parece claro que la espiritualidad antigua —con el nombre de «filosofía» ya en 1983 y 1984 — adquiere un carácter político al introducirse como diferencia en el espacio político. Si la parresía cínica va a ser para Foucault un ejemplo privilegiado es porque de manera muy evidente hace de la autoconstitución del sujeto ético un asunto ya de entrada político pero también porque permite pensar en el límite esa situación de una exterioridad o alteridad radical que, sin embargo, se corporeiza o materializa, haciéndose valer en el contexto histórico-político ${ }^{39}$.

La relación entre filosofía y política es «constituyente» de ambas en su comienzo histórico - «...esta relación necesaria, fundamental, que sin duda es constituyente de la filosofía y de la práctica política en Occidente»— pero, al mismo tiempo, posee para Foucault un valor en cierto modo supratemporal: es «un rasgo recurrente, permanente y fundamental», «esencial para toda la filosofía» y no sólo referido a tiempos de Platón sino «también en la hora actual» ${ }^{40}$, hasta el punto de que la relación necesaria, aunque diferencial, de la filosofía y la política, es vista por Foucault como la propia fuerza o vida de la filosofía, su manera de poder acontecer de modo renovado: «¿no es como parresía, que habría que retomar sin cesar, como la filosofía sin cesar recomienza?» ${ }^{41}$. No es

38 «...pienso que hay que sospechar que es imposible constituir hoy una ética de sí, pero que constituirla es una tarea urgente, fundamental, políticamente indispensable, si es verdad que después de todo no hay otro punto, primero y último, de resistencia al poder político más que en la relación de sí a sí». (L'Herméneutique du sujet, p. 241).

39 La vida del cínico es, así, atravesada por lo político. Lorenzini, D., (o. c., pp. 248254) ha mostrado que el plano ético no es, en los cínicos, presupuesto como condición o fundamentación del plano político, sino que es inmediatamente político. Según este autor, ello lleva a los cínicos a proponer lo que se podría interpretar como una «transfiguración» de la política, según la cual el espacio social se vería por entero politizado. Habría que pensar, no obstante, si no se trata justamente de lo contrario, de una delimitación de la política.

40 Las anteriores expresiones se encuentran en Le gouvernement de soi et des autres, pp. 266-267.

41 Ibíd., p. 321. Sobre ese recomienzo me permito remitir a «Foucault and the Recommencement of Philosophy», en: CLCWeb: Comparative Literature and Culture, 20/4, 2018. 
fácil determinar cuál es el sentido de ese recomienzo al que Foucault se refiere. En el mismo pasaje al que pertenece la cita anterior y en continuidad con ella, se da la explicación esperada de por qué ese curso, dedicado a la cuestión de la parresía antigua, había comenzado con dos lecciones dedicadas al texto kantiano Was ist Aufklärung?: al plantearse en él la cuestión de la actualidad del discurso filosófico, su «relación sagital» con el presente al cual pertenece, estaría de alguna manera reiniciando la relación filosofía-política que es constitutiva de la parresía filosófica descubierta por Platón ${ }^{42}$. El «cinismo transhistórico» de que hablará Le courage de la vérité expresará la misma idea, ahora planteada, no en términos de un recomienzo eventual (événementiel) de la filosofía aunque sí de un acto de naturaleza filosófica que reaparece con distintos "perfiles» como actitud. En cualquier caso, parece que esta idea de la filosofía sirve bien para describir la posición teórica misma de Foucault hasta el final ${ }^{43}$.

\section{LA CONEXIÓN ENTRE ESPIRITUALIDAD Y NEGATIVIDAD}

«Lo real de la filosofía» platónico reside en un suplemento al logos, de carácter práctico-material —ergon vinculado con la política一, y que, en el caso de Sócrates, tal como aparece en el análisis del Laques realizado en el último curso, presupone la «homofonía» entre el decir-veraz y el modo de vida (bios) ${ }^{44}$. En el caso del cinismo, la homofonía socrática es llevada al límite y desbordada en una identificación de logos y bios, más aún, una verdadera kenosis del logos en el bios que, de ese modo, se hace manifestativo y testimonial, realizativo y activo: el cinismo hace de la vida una manifestación de la verdad; o, visto por el otro lado, «se hace visible el cuerpo mismo de la verdad ${ }^{45}$, adquiriendo ésta una fuerza propia que no es, sin embargo, la mera fuerza de la convicción racional sino la fuerza que permite a la verdad intervenir materialmente en el mundo ${ }^{46}$.

Pero Foucault parece plenamente consciente de que la fuerza crítica que la verdad adquiere en la vida del cínico procede de un elemento de negatividad.

42 «...si he comenzado el curso de este año por Kant, es una cierta manera, para la filosofía, de tomar conciencia, a través de la crítica de la Aufklärung, de los problemas que eran en la Antigüedad los de la parresía». (Le gouvernement de soi et des autres, p. 323).

43 En una de las últimas entrevistas de Foucault, de marzo de 1984, concedida a Jamin Raskin, afirma: «...los filósofos deben mantener una cierta distancia crítica con respecto a los políticos». («A Last Interview with French Philosopher Michel Foucault», en: City Paper, 27 julio 1984, p. 18.)

44 Ver sobre ello Le courage de la vérité, pp. 136, 156.

45 Ibíd., pp. 160, 283.

46 Se trata de la «fuerza socrática», del ischus cínico, una noción importante en el cinismo (ver Goulet-CAzé, M.-O., L'ascèse cynique, Vrin, Paris 1986, pp. 34, 145, 147) pero también se trata de un problema fundamental en la trayectoria teórica de Foucault: el de un «poder de la verdad» que no se reduzca a la verdad del poder, asunto especialmente destacado por G. Deleuze en «Les plissements ou le dedans de la pensée (Subjectivation)», en: Foucault, Minuit, Paris 1986, p. 101. 
La conexión entre espiritualidad y negatividad es un tema que recorre buena parte de la tradición filosófica. En la manera en que Foucault reconstruye esta conexión está sin embargo próximo a Jan Patočka, una de cuyas obras Platón y Europa (edición francesa de 1983) es citada por Foucault en Le courage de la

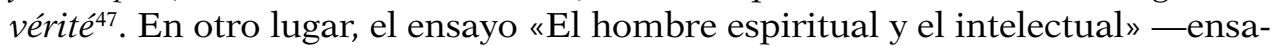
yo de 1975 publicado en francés en 1990-, poniendo como ejemplo a Sócrates, Patočka define al «espiritual» como aquél que «vive expresamente a partir de lo negativo», exponiéndose a ello y sosteniéndose en ello. La negatividad de lo espiritual es también para Patočka una fuerza transformadora, por lo que, según él, cabe pensar en una "política del hombre espiritual»: aunque no es un político en el sentido corriente del término, el espiritual lo es en otro sentido, según el autor checo, al optar por vivir con una actitud que desde el punto de vista del mundo es intolerable: «La vida en esta actitud es precisamente lo que las potencias positivas de la realidad no toleran y no quieren ver... $\gg^{48}$. En el ensayo de los años 50, «El platonismo negativo», Patočka remitía el origen de la metafísica occidental a la «experiencia de la libertad» descubierta por Platón. En ese ensayo, como su título indica, se propone una interpretación no metafísica y no dualista de Platón en cuyo núcleo estaría más bien esa experiencia de libertad con respecto a lo dado, experiencia de un chorismós que no diferencia dos ámbitos de realidad, sino que es «una distinción en sí», «la separación absoluta como tal». La idea de una filosofía que interviene en la política a través de su diferencia con ella, quizás no queda lejos de aquí. En el platonismo negativo, la Idea es una fuerza de distanciamiento o de retirada con respecto a lo dado y, por tanto, un poder de creación de lo nuevo: «una fuerza de desobjetivación y de desrealización donde nacen todas nuestras capacidades de lucha contra "la realidad pura y simple" que tendería a imponerse a nosotros como ley absoluta, irrevocable, insuperable» ${ }^{49}$.

\section{El HEROÍSMO FILOSÓFICO COMO MODELO DE LA ACCIÓN REVOLUCIONARIA}

En el caso del cinismo, tal como es interpretado por Foucault en Le courage de la vérité, lo que se realiza en la vida del cínico y le da a ésta su poder de corrosión y de crítica, es una diferencia, una alteridad con respecto al mundo

47 Ver Ibíd., p. 119. Foucault le reconoce el mérito de reinterpretar la historia de la filosofía a partir de la idea platónica de cuidado del alma pero le critica su supuesta confusión del sujeto del cuidado con la realidad metafísica del alma.

48 «L'homme spirituel et l'intellectuel», en: Liberté et sacrifice. Écrits politiques, J. MiLlon, Grenoble 1990, p. 256 ; ver las pp. 246-248.

49 «Le platonisme négatif», en: Liberté et sacrifice. Écrits politiques, p. 89. Ver, en este ensayo, las pp. 82-98. En el ensayo, contenido también en esta obra, "Remarques sur la position de la philosophie dans et en dehors du monde» (1934), РАтос̌KA hace al final una defensa del heroísmo filosófico en términos convergentes con la posición de Foucault. Ver p. 25 de la edición citada. 
presente que, sin embargo, se presenta y materializa, en tanto que tal diferencia, en una forma de existencia o actitud que sólo puede ser vista como inaceptable y escandalosa desde el lado del mundo. Foucault lo formula con mucha claridad: «...el principio del cinismo es justamente decir que la verdadera vida es la vida otra $»^{50}$. O, como afirman las últimas palabras del manuscrito de este último curso: «no hay instauración de la verdad sin una posición esencial de la alteridad (...); no puede haber verdad más que en la forma del otro mundo y de la vida otra $\aleph^{51}$. La posición cínica parece arrojar luz desde esta radicalidad a la relación necesariamente diferencial que la filosofía mantiene con la política y que constituye, como veíamos, «lo real de la filosofía». El cinismo parece aportar a la parresía filosófica platónica un vínculo entre la negatividad de una alteridad radical y la fuerza real que esa negatividad puede llegar a adquirir cuando se la hace valer en el mundo contra el mundo. Como si los cínicos, a base de extremar la experiencia filosófica, hubieran descubierto la manera de convertirla en el punto de apoyo arquimédico para mover el mundo. No es extraño por ello que Foucault vea en el cinismo «la esencia del heroísmo filosófico», el cual, aun tratándose de "una leyenda filosófica», reconoce que ha tenido una enorme influencia hasta nuestros días, en que se ha desplazado desde el plano filosófico al campo político en la forma de la vida revolucionaria ${ }^{52}$. Podría interpretarse que, en gran medida, la intención de Foucault en este momento ha sido pensar cómo se puede reanimar la vida revolucionaria con esa leyenda filosófica y, viceversa, cómo se puede realizar prácticamente la experiencia de la libertad, que es esencial en la filosofía. Y que ambas cosas se encierran en la idea de un «militantismo en el mundo contra el mundo» ejemplificado de manera privilegiada en el cinismo. En ello parece encerrarse, para Foucault, el doble problema de cómo concebir en la actualidad al sujeto filosófico y al sujeto práctico (ético y político), o quizás la identidad de uno y otro, de ontología y de crítica.

La idea de un heroísmo filosófico obedece a un antiguo «paradigma heroico del filósofo» — como lo denomina N. Loraux — que remonta a Heracles, con quien es comparado Sócrates, por su fuerza de resistencia ante las adversidades,

$50 \quad$ Le courage de la vérité, p. 287.

51 Ibid., p. 311. El texto, para ser coherente con la distinción hecha en lecciones anteriores entre «experiencia metafísica del mundo» y "experiencia histórico-crítica de la vida» (p. 289), debería decir «mundo otro» y no «otro mundo», ya que se está refiriendo a la experiencia cínica.

52 Ver Ibíd., pp. 195-196. En este lugar, Foucault se refiere al Fausto de Goethe como último momento de esa leyenda filosófica, momento de desaparición de la vida filosófica, que se convierte en vida profesoral (ver p. 196). Evidentemente, el heroísmo filosófico reaparece en la actualidad como una forma de existencia en otros ámbitos: la vida revolucionaria, como se dice en esta página, y en el arte moderno. A esas «posteridades» del cinismo dedica Foucault la lección anterior (pp. 163-176). Sobre la relación entre la «ontología de la literatura» del primer Foucault y la idea de subjetividad ético-política del último, me permito remitir a «Ontologie de la littérature et subjectivité chez Foucault», en: Çédille. Revista de estudios franceses, $\mathrm{n}^{\circ} 17,2020$, pp. 227-241. 
y Diógenes, cuyo modo de vida se caracteriza, como el del héroe, por poner la libertad por encima de todo. Por su parte, Heracles es considerado un filósofo pitagórico, por lo que parece característico de este paradigma el «intercambio» entre el filósofo heroico y el héroe filosófico ${ }^{53}$. Según Loraux, el «acontecimiento ideológico capital» que supuso la sustitución del ciudadano por el filósofo como paradigma del hombre perfecto, en el que Platón y los cínicos tuvieron el mayor protagonismo, condujo a un héroe asceta en el que el paradigma heroico del filósofo se desplazó hacia la teoría de la acción ${ }^{54}$. Después haremos referencia a la importancia que adquiere para el último Foucault el problema de la voluntad pero ahora importa destacar lo singular de la voluntad heroica: ésta no se limita a un objeto y es, como afirma M. Blanchot, «una acción liberada de todas las pequeñeces de la acción», lo que produce en su caso un paradójico intercambio entre acción y contemplación ${ }^{55}$. En ese intercambio parece operar de manera muy esencial la oposición radical entre el héroe y el mundo, como si fuera esa diferencia irreductible con el mundo, alcanzada tras una epojé del mismo, precisamente el resorte más poderoso de la acción, la manera en que lo que no posee fuerza, el espíritu, puede tener poder sobre el poder. Pero esa oposición al mundo es precisamente un rasgo estructural de la filosofía: es nítida en el caso de los cínicos, filósofos anticonvencionales y críticos radicales con el estado actual del mundo, pero está presente de modo germinal en la experiencia de la libertad platónica y en su idea de la práctica filosófica, tal como antes veíamos. En ninguno de los casos esa oposición filosófica obedece al mero deseo gratuito de problematizar y, en gran medida, es lo contrario del mero resentimiento ${ }^{56}$.

Vemos con claridad que en todo heroísmo operaría esa estructura filosófica pero lo difícil es ver a qué necesidad ontológica obedece esa acción militante contra el mundo, ver lo que en ella hay de irreductible a una mera acción arbitraria y subjetiva, el modo en que la voluntad militante no sólo niega el mundo sino que de alguna manera se rige por él y lo afirma positivamente. Carlyle, en su estudio clásico sobre Los héroes (1841), confirmaba ese carácter «filosófico» del heroísmo: el espíritu del heroísmo es vivir plena y sinceramente en realidad y penetrar en la esencia de las cosas, lo que le lleva a estar «en eterna protesta y

53 Ver LoRAux, N., «Sócrates, Platón, Heracles: a propósito de un paradigma heroico del filósofo», en: Las experiencias de Tiresias, Acantilado, Madrid 2004, pp. 358-381.

54 Ver Ibíd., p. 380. Sobre ese acontecimiento ideológico, ver p. 378.

55 «...el héroe es el testigo de una ambición dos veces imposible ya que, si quiere ir más lejos que su fuerza, quiere también encontrar en el ejercicio de esta fuerza el éxtasis y la dignidad suprema que sólo procura el rechazo de la acción, lo que los occidentales llaman la contemplación y los orientales el no-saber». (BцANснот, M., "Considérations sur le héros», en: Journal des débats, 9 septembre 1942, p. 3).

56 Como ha mostrado A. Camus en L'homme révolté (1951), con quien los análisis de Foucault sobre las posteridades del cinismo en el arte moderno guardan algunos parentescos. Véanse, en la traducción española («El hombre rebelde», en: CAmus, A., Ensayos, Aguilar, Madrid 1981), las pp. 568-570. 
batalla con el mundo ${ }^{57}$. Frente al mundo, falso y gratuito, el héroe es verdadero y necesario: «hombre verdadero, rodeado ordinariamente de un mundo de inconsistencias.... ${ }^{58}$. Igualmente, en la forma de vida desenraizada del cínico, y hasta en su misma corporalidad desnuda, «estatua visible de la verdad» —con la bella expresión de Foucault-, se hacen coincidir el escándalo y la subversión con la afirmación de la razón objetiva o material del mundo - en el sentido que le da Horkheimer-, con su en-sí, de manera que el trasvase del logos al bios, que se produce en los cínicos, no es más que la realización ontológica del logos en un mundo circunstancial y gratuito ${ }^{59}$. Esa realización del logos verdadero del mundo y de la vida, en el mundo presente y en la vida particular del cínico, es por sí misma revolucionaria.

\section{El LEVANTAMIENTO IRANí Y LA ESPIRITUALIDAD POLÍTICA}

El mundo al que se enfrenta el cínico, por su gratuidad, se parece mucho al nuestro. Para el cínico, el mundo común está desprovisto de sentido y racionalidad, sometido a los caprichos de la fortuna (tyché) y, ante él, sólo una ascesis extrema puede dar la fuerza (ischus) para resistir ${ }^{60}$. Pero, al mismo tiempo, la acción militante contra el mundo no se deduce en ningún sentido del mundo al cual se opone. El mundo como totalidad funcional, a pesar de la aparente necesidad con la que todo ocurre dentro de él, es visto por el militante como radicalmente infundado y contingente. Por ese motivo, vista desde el mundo, la acción militante sólo puede ser gratuita, ya que se apoya exclusivamente en la negatividad. Es lo que descubre Foucault en el levantamiento que se produjo en Irán en 1978 contra el régimen del Sha: «...me parece bien que esta gente [historiadores, economistas, sociólogos, etc.] expliquen las razones, los motivos,

57 Carlyle, T., Los héroes (1841), Sarpe, Madrid 1985, p. 110. Como ejemplos, de entre los innumerables pasajes de esta obra que se podrían citar en este mismo sentido: «...el principio y el fin, el alfa y el omega, el espíritu de todo heroísmo: la de penetrar, a través de las cosas, en la esencia de las cosas mismas». (p. 80); «héroe es aquél que vive dentro de la esfera íntima de las cosas, en lo verdadero, en lo divino, en lo eterno, en lo invisible a los más...» (p. 174). Por eso, la sinceridad es el ser mismo del héroe: «héroe significa hombre sincero» (p. 147).

${ }^{58}$ Ibíd., p. 216.

59 La estudiosa del cinismo, M.-O. Goulet-Cazé ( «Foucault et sa visión du cynisme dans Le courage de la vérité», en: LorenzinI, D. y otros, o. c., p. 110), se ha referido a cómo, de las acepciones del logos, palabra y razón, los cínicos privilegian la segunda, el logos-razón, identificando a la razón con la naturaleza. Pese al negativismo y a la reducción al mínimo de la doctrina filosófica en los cínicos, puede verse en ellos una afirmación metafísica de gran radicalidad. Sobre ese concepto de razón, opuesto a la razón subjetiva o procedimental, véase, por ejemplo, M. HorkHeimer, «Sobre el concepto de razón», en: Sociológica, Taurus, Madrid 1966, pp. 201-212.

60 Véase Goulet-Cazé, M.-O., Ibíd., p. 114. La autora señala en este lugar cómo se habría beneficiado el análisis de Foucault de haber reparado en este importante motivo cínico de la Fortuna (Tyché). Ver también de la misma autora L'ascèse cynique, pp. 145-150. 
los temas, las condiciones en que se han desarrollado [las acciones subversivas] pero, una vez más, el gesto mismo de levantarse me parece irreductible en relación con esos análisis» ${ }^{61}$. En estos años, y sin duda en relación con estos acontecimientos en Irán, Foucault ha pensado lo que puede ser la acción heroica o militante distinguiendo lo que llama "levantamiento» (soulèvement), de la noción de revolución —una distinción que recuerda la que hace Max Stirner entre revolución y revuelta- La revolución, en su acepción tanto liberal como marxista no deja de suponer un esquema reapropiativo de la esencia humana y el despliegue de un proceso histórico global y unitario sometido a una legalidad o a un programa. El levantamiento, por el contrario, no obedece a nada preexistente, ni siquiera pertenece a la continuidad del tiempo y de la historia sino que pertenece al régimen de los acontecimientos (événements); es, según Foucault, «lo que, en la historia, escapa a la historia», «es el instante, la fractura, el desgarro, la interrupción»: "[la revolución] se aloja en la historia, hace en ella su cama y, finalmente se acuesta en ella. El levantamiento, cortando el tiempo, coloca a los hombres en la vertical de su tierra y de su humanidad ${ }^{62}$.

El levantamiento iraní es para Foucault el ejemplo histórico de cómo el punto de apoyo para cambiar el mundo no puede ser ningún hecho sometido al orden causal y de las razones sino una alteridad con respecto a todo ello, una exterioridad que, sin embargo, es inmanente al mundo mismo y está presente en él a ras de la existencia - como va a estar presente la alteridad de la verdad en la vida del cínico-, pero que es capaz de operar en él de un modo radicalmente transformador. En el artículo sobre el levantamiento iraní publicado en Le Monde en mayo de 1979, lo planteaba Foucault con claridad:

...el hombre que se levanta finalmente es sin explicación; hace un desgarro que interrumpe el hilo de la historia y sus largas cadenas de razones, para que un hombre pueda «realmente» preferir el riesgo de la muerte a la certeza de tener que obedecer. [...] Todas las formas de libertad adquiridas o reclamadas, todos los derechos que se hacen valer [...] tienen sin duda ahí un punto último de anclaje, más sólido y más próximo que los «derechos naturales» ${ }^{63}$.

Un punto de anclaje «más sólido y más próximo», dice Foucault, porque aunque se trate de una alteridad radical con respecto al mundo, tiene que ver, sin embargo, "con la manera en que era vivido» el levantamiento, «lo que pasaba en la cabeza» de sus protagonistas. El levantamiento es el acontecimiento

61 «Entretien inédite avec Michel Foucault 1979», en: Foucault Studies, n 25, octubre 2018, p. 363.

${ }_{62}$ «Vivre autrement le temps» (1979), en: Dits et écrits, vol. III, p. 790. Véase, además, sobre el «levantamiento»: «L'esprit d'un monde sans esprit» (1979), en: Ibíd., p. 749; «Inutile de se soulever?» (1979), Ibíd., pp. 790-793. Sobre las luchas actuales y su carácter «anárquico»: «Pourquoi étudier le pouvoir ?: la question du sujet», en: Dreyfus, H.-L. y Rabinow, P. (eds.), Michel Foucault, un parcours philosophique, Gallimard, Paris 1984, p. 301. De M. STIRNER, puede verse sobre ello: El único y su propiedad, Orbis, Barcelona 1985, vol. II, p. 169.

63 «Inutile de se soulever», p. 791. 
por el que «la subjetividad se introduce en la historia y le da su aliento» ${ }^{64}$. A pesar de que estas expresiones podrían hacernos pensar en una reafirmación del sujeto soberano por parte de Foucault, parecen apuntar a un asunto bastante diferente. No se trata tanto del sujeto de la revolución como del «aspecto sombrío y solitario de las luchas», según lo denomina en la entrevista con R. Yoshimoto de abril de $1978^{65}$. Aspecto normalmente ocultado por lo que llama aquí Foucault «la profecía», es decir, la idea marxista de la revolución — de la que se trata en especial en esta entrevista-, sólo se le habría hecho justicia en el ámbito de la literatura, no en el de la teoría filosófica. La interpretación de Foucault en este momento es que la filosofía no ha ser la única palabra acerca de cómo deben o pueden ser las cosas, "el único pensamiento normativo", sino que hay otras palabras, "un número incalculable de sujetos parlantes» que quieren hablar y «una experiencia innumerable» que ha de ser escuchada: "Creo que la tarea de alguien que practique la filosofía en Occidente es prestar oído a todas esas voces ${ }^{66}$. Este aspecto existencial de la experiencia política es también el destacado por Foucault en la larga entrevista con D. Trombadori, de final de ese mismo año, en referencia a lo que percibió años atrás en Túnez: «Para esos jóvenes, el marxismo no representaba solamente una manera mejor de analizar la realidad sino que, al mismo tiempo, era una especie de energía moral, de acto existencial completamente extraordinario ${ }^{67}$. Sea en el contexto político, sea en el filosófico, en el cruce de ambos, la intuición de Foucault es que la máxima radicalidad no está en las meras doctrinas sino en este otro plano, existencial: «la radicalidad concierne a la existencia» ${ }^{68}$. Que es aquí donde se introduce lo nuevo en el mundo y en la historia, y que esa alteridad del mundo-otro no es la mera negación lógica de lo que hay, ni la expresión arbitraria de los deseos de una subjetividad desligada del mundo, ni lo que se deduciría de una mera doctrina acerca de cómo debe ser el mundo. Sólo desde ese ámbito «existencial» puede abordarse el doble problema de qué hay que pensar y de qué podemos hacer —o de cómo podemos pensar de otra manera y dejar de hacer lo que hacemos-. En el plano estrictamente político, la enseñanza del levantamiento iraní — «el alma del levantamiento»— parece residir, para Foucault, en que aunque reconozcamos la necesidad de un cambio de régimen corrupto, de sistema político, etc., el cambio más importante, verdadera condición de los otros cambios más visibles, es el que afecta a nuestra experiencia,

$64 \quad$ Ibid., p. 793.

65 «Méthodologie pour la connaissance du monde: comment se débarraser du marxisme», en: Dits et écrits, vol. III, p. 615.

66 Ibíd., p. 616.

67 «Entretien avec Michel Foucault», en: Dits et écrits, vol. IV, p. 79.

68 En la entrevista de febrero de 1978 con P. PASQuino, «Précisions sur le pouvoir. Réponses à certaines critiques», afirma Foucault: «...la acción política pertenece a un tipo de intervención totalmente diferente de estas intervenciones escritas y librescas, es un problema de grupos, de compromiso personal y físico. Uno no es radical porque haya pronunciado algunas fórmulas, no, la radicalidad es física, la radicalidad concierne a la existencia». (Dits et écrits, vol. III, p. 634). 
y que «no habrá revolución real más que a condición de ese cambio radical en nuestra experiencia ${ }^{69}$.

La polémica noción de «espiritualidad política» que Foucault acuña en estos años parece obedecer a esa misma intuición. Aunque surge en el contexto de la interpretación de los acontecimientos en Irán, apunta a la problemática que recorre también las últimas investigaciones de Foucault. En el artículo de octubre de 1978 publicado en Le Nouvel Observateur sobre la situación en Irán, Foucault se refiere a dos movimientos complementarios que permiten entenderla. Por un lado, un movimiento de carácter utópico, de creatividad y de creación política, al que ha servido allí la religión - $-\mathrm{y}$, por tanto, nada que pueda interpretarse como la mera aplicación política de una dogmática doctrinal- . Por otro lado, y como recíproco del primero, «el [movimiento] que permitiría introducir en la vida política una dimensión espiritual», haciendo posible una experiencia, la de la «espiritualidad política», que en occidente se perdió, según Foucault, después del renacimiento y de las crisis religiosas en la modernidad $^{70}$. Parece claro que, para Foucault, la apertura de esa dimensión de espiritualidad en la política no es la imposición de la religión en el espacio público, sino la introducción de un principio irreductible al régimen político existente, así como al gobierno islámico que se derivaría del levantamiento ${ }^{71}$. Que se trata de un principio de alteridad para Foucault parece confirmarlo el modo en que interpreta en noviembre de 1978 el papel peculiar que en ese momento está jugando Jomeini en los acontecimientos: Jomeini «no está allí», «no dice nada», "no es un hombre político» ${ }^{72}$. Es verdad que Foucault en ese momento se equivoca: "no habrá partido de Jomeini, no habrá gobierno Jomeini», pero es significativo que precisamente interprete el levantamiento en términos de ese negativismo de su supuesto líder. La insurrección iraní tendría el valor ejemplar de encarnar un modo de acción que hace valer, no «otro mundo» sino

69 «L'esprit d'un monde sans esprit», p. 749: «Sobre todo, hemos de cambiar nosotros mismos. Es necesario que nuestra manera de ser, nuestras relaciones con los otros, con las cosas, con la eternidad, con Dios, etc., sean cambiadas completamente, y no habrá revolución real más que a condición de ese cambio radical en nuestra experiencia». En la p. 754: «Lo que ha dado su intensidad al movimiento iraní ha estado en un doble registro. Una voluntad colectiva políticamente muy afirmada y, de otra parte, la voluntad de un cambio radical en la existencia».

70 «A quoi rêvent les Iraniens?» (1978), en: Dits et écrits, vol. III, p. 693. El pasaje continúa: «...: hacer que esta vida política no sea, como siempre, el obstáculo de la espiritualidad sino su receptáculo, su ocasión, su fermento». En la p. siguiente: «¿Qué sentido tiene, para los hombres que viven allí, buscar, incluso al precio de su vida, esta cosa cuya posibilidad hemos olvidado nosotros desde el renacimiento y las grandes crisis del cristianismo: una espiritualidad política?».

71 Ante las críticas y los malentendidos de que fueron objeto las primeras crónicas de Foucault, en el artículo publicado en Le Monde en mayo de 1979, aclara: «La espiritualidad a la cual se referían los que iban a morir no tiene medida común con el gobierno sangrante de un clero integrista». «De ahí, justamente, la necesidad de resaltar lo que hay de no reductible en un movimiento tal». («Inutile de se soulever?», p. 793)

72 Ver «Le chef mythique de la révolte de l’Iran» (1978), en: Dits et écrits, vol. III, p. 716. 
una alteridad contenida de modo inmanente en este mundo, y que reclama tanto una negación como una afirmación del mismo ${ }^{73}$. Un modo de acción que parece muy próximo al efecto escandaloso que la vida cínica produce en el mundo al encarnar la vida-otra y el mundo-otro, tal como Foucault ha descrito en el último curso en el Collège de France.

\section{ESPIRITUALIDAD POLÍTICA Y ACTITUD CRÍTICA: EL PROBLEMA DE LA VOLUNTAD}

En la entrevista con Farès Sassine de agosto de 1979, Foucault remite a la lectura de la obra de $\mathrm{E}$. Bloch, El principio esperanza, para explicar las razones de su interés por los acontecimientos iraníes: en esa obra se estudiaba el surgimiento en la edad media y al comienzo de la modernidad de la percepción — de origen religioso, pero que ha estado en el origen de la idea misma de revolución- de «...otro mundo aquí abajo, la percepción de que la realidad de las cosas no está definitivamente instaurada y establecida sino que puede haber, en el interior de nuestro tiempo y de nuestra historia, una apertura, un punto de luz y de atracción que nos da acceso, desde este mundo a un mundo mejor» ${ }^{74}$. Esa percepción y la experiencia a la vez política y religiosa a la que da lugar, la espiritualidad política, tuvo su plasmación en las revueltas populares de los siglos XII-XIII y sobre todo en los siglos XV-XVI en las guerras de religión. Tiene, por tanto, mucho que ver con el surgimiento, en occidente, de lo que en el curso de 1977-1978, Sécurité, territoire et population, llamaba «contra-conductas» y la conferencia «Qu'est-ce que la critique? Critique et Aufklärung» (1978) ha llamado la «actitud crítica», es decir, el surgimiento en el contexto de la gubernamentalidad pastoral occidental de «revueltas de conducta» que, oponiéndose a los modos establecidos de conducción o gobierno, proponían positivamente otros modos de conducción y otras «formas de existencia»" La experiencia de la espiritualidad política

73 «...un movimiento que no se deja dispersar en unas opciones políticas, un movimiento atravesado por el aliento de una religión que habla menos del más allá que de la transfiguración de este mundo». (loc. cit.). C. JAMBET ("Constitución del sujeto y práctica espiritual. Observaciones sobre la historia de la sexualidad», en: Balibar, E., Deleuze, G. y otros, o. c., p. 228) ha visto bien que la interpretación que Foucault ha hecho de la espiritualidad política islámica tiene que ver con su interrogación «trascendental» acerca de las condiciones de posibilidad de la insurrección, sobre cómo ésta puede estar determinada por «acontecimientos producidos en el cielo», haciendo que la historia quede suspendida por «acontecimientos mesiánicos cuyo lugar no es el mundo de los fenómenos conocidos por la ciencia». Jambet se refiere al papel que en la espiritualidad política islámica tiene la «metahistoria» — «hierohistoria» o «transhistoria»— pero parece, sin embargo, que Foucault interpreta esa espiritualidad más en términos del mundo-otro cínico que del otro-mundo islámico. Ver también de este autor: «Retour sur l'insurrection iranienne», en: L'Herne. Foucault, Cahiers de l'Herne, Paris 2011, pp. 372-376.

74 «Entretien inédit avec Michel Foucault 1979», pp. 351-352.

75 Véase «Leçon du $1^{\text {er }}$ mars 1978», en: Sécurité, territoire, population. Cours au Collège de France 1977-1978, Gallimard/Seuil, Paris 2004, pp. 195-232. La conferencia mencionada, 
occidental sirve a Foucault para comprender «en analogía» con ella lo ocurrido en Irán pero, al mismo tiempo, la reflexión sobre esos acontecimientos iraníes sirve para poder asistir en vivo a una experiencia ya perdida para Occidente ${ }^{76}$.

En otra intervención de los mismos meses, la «Table ronde du 20 mai 1978», y en el contexto de algunas aclaraciones de carácter metodológico, Foucault hace de nuevo referencia a esta noción de «espiritualidad política». Los regímenes de prácticas son analizados por él en atención a un doble eje de su racionalidad, la «codificación-prescripción»—o «juridicción»—, que se refiere a cómo se regulan las maneras de hacer o conductas, es decir, cómo se gobiernan, y la «veridicción», que tiene que ver con la producción de discursos verdaderos que fundamentan, justifican o transforman esas maneras de hacer: «mi problema es saber cómo se gobiernan los hombres (ellos mismos y a los otros) a través de la producción de verdad $»^{77}$. Los análisis de Foucault están entonces interesados en estudiar la interconexión histórica entre la veridicción y la juridicción, cómo una determinada partición verdadero/falso afecta a una manera de gobernar y/o gobernarse y como una forma de gobierno específica afecta a esa partición de lo verdadero y de lo falso. Foucault es consciente de que este tipo de análisis posee una importancia práctica enorme porque toca al núcleo mismo de la política: «¿No es el problema político más general el de la verdad?» ${ }^{78}$. A partir de esos presupuestos teóricos o analíticos, es definida en ese lugar la «espiritualidad política» en términos de la voluntad de intervenir precisamente en esa conexión entre verdad y gubernamentalidad con el fin de producir una alteración de la realidad histórica:

La voluntad de fundar enteramente de nuevo la una [la manera de separar lo verdadero y lo falso] y la otra [la manera de gobernarse a sí mismo y a los otros], la una por la otra (descubrir una separación — partage- completamente diferente por otra manera de gobernarse, y gobernarse de manera completamente diferente a partir de otra separación), eso es la «espiritualidad política» ${ }^{79}$.

del 27 de mayo de 1978, publicada por primera vez con el título «Qu'est-ce que la critique? (Critique et Aufklärung)» en el Bulletin de la societé Française de philosophie, año 84, ${ }^{\circ} 2$, abril-junio 1990, pp. 35-63, ha sido reeditada recientemente en francés por H.P. FRUCHAUd y D. LoREnZINI como "Qu'est-ce que la critique?» en: Foucault, M., Qu'est-ce que la critique? Suivi de La culture de soi, Vrin, Paris 2015, pp. 35-80.

76 Ver sobre ello: «Entretien inédit avec Michel Foucault 1979», pp. 357-358. En la p. 357: «...he visto allí un movimiento muy curioso, muy raro, y que no se puede comprender, creo, más que en analogía con las cosas pasadas aquí, la espiritualidad política».

77 «Table ronde du 20 mai 1978», en el colectivo L'impossible prison, Seuil, Paris 1980, p. 47.

Ibíd., p. 51.

79 Loc. cit. J. CAVAGnIS ( «Michel Foucault et le soulèvement iranien de 1978. Rétour sur la notion de "spiritualité politique"», en: Cahiers philosophiques, 2012/3, n ${ }^{\circ} 130$, p. 53, nota 8) ha señalado que esta definición "fría» que se da aquí de la espiritualidad política puede explicarse por el intento de Michel Foucault de evitar los malentendidos de que anteriormente fue objeto esta noción: la entrevista, probablemente corregida más tarde, en 1980, cuando se publicó, podría haber modificado la noción en ese sentido menos comprometido. 
La espiritualidad política parece entonces apuntar a un modo de acción o de intervención en la realidad capaz de afectar a sus condiciones históricas, al lugar - que Foucault va a denominar en seguida «juegos de verdad»— en el que se articula la realidad histórica como experiencia ${ }^{80}$. No sería tanto una intervención más en el mundo, que afectara a la gestión de los regímenes vigentes y que pudiera encajarse en las formas de experiencia ya existentes, cuanto la acción que puede transformar esas formas de experiencia y, de ese modo, operar un cambio en el mundo. ¿Cuál es el resorte de esa acción transformadora? Si las resistencias han de ser algo diferente de la reacción a una acción previa de signo opuesto, reproductora como ella de lo existente, han de apoyarse en una fuerza diferente. Hemos visto anteriormente que en gran medida para Foucault esa fuerza es la de la propia diferencia: la alteridad de una diferencia teológica en el caso del levantamiento chiita iraní - si bien interpretada por Foucault en clave mística y existencial, no propiamente doctrinal-religiosa, quizás por la influencia del prestigioso estudioso de la espiritualidad chiita, H. Corbin ${ }^{81}$; o la alteridad de una diferencia filosófica, constitutiva desde Platón de «lo real de la filosofía», y en la extremación cínica, materializada en la verdad como escándalo para el mundo. El último Foucault, incluyendo en él al intérprete de los acontecimientos en Irán, parece estar descubriendo que las resistencias al poder exigen, como ve muy bien Deleuze, más allá de la verdad de la fuerza o del poder, un "poder de la verdad» irreductible a los regímenes existentes, una verdad cuya fuerza reside en su alteridad. Pero, más aún, está descubriendo que la fuerza de la diferencia sólo puede operar en el mundo si tiene como punto de apoyo la gratuidad o sin razón del mundo, tal como se pliega en la libertad de los sujetos y, por tanto, en su acción voluntaria. En varias declaraciones de final de los setenta, Foucault reconoce la importancia del problema de la voluntad, insuficientemente tratado por él hasta ese momento ${ }^{82}$. El reconocimiento del aspecto voluntario de las resistencias no lleva a Foucault, sin embargo a reintroducir la noción de voluntad como la categoría metafísica tradicional, o como una noción naturalista o meramente jurídica ${ }^{83}$.

La definición que la «Table ronde du 20 mai 1978» daba de la «espiritualidad política» la interpretaba en términos de voluntad: «la voluntad de fundar enteramente de nuevo...». También las nociones próximas de "contra-conductas» y de «actitud crítica», parecen apuntar en esta dirección. La «actitud crítica», en

80 «...juegos de verdad a través de los cuales el ser se constituye históricamente como experiencia». (L'usage des plaisirs, p. 13)

81 Véase sobre ello los artículos citados de C. JAMBET y el de J. CAVAGnis.

82 Se puede ver por ejemplo en: «Méthodologie pour la connaissance du monde: comment se débarraser du marxisme», en: Dits et écrits, vol. III, pp. 603 ss. ; "Entretien inédit avec Michel Foucault 1979», pp. 368 ss.; «Qu'est-ce que la critique?» («Qué es la crítica? Crítica y Aufklärung», en: Foucault, M., Sobre la Ilustración, Tecnos, Madrid 2006, pp. 46-47).

83 Véase Cremonesi, L., Irrera, O., Lorenzini, D. y Tazzioli, M., «Foucault, the Iranian Uprising and the Constitution of a Collective Subjectivity», prefacio al libro Foucault and the Making of Subjects (Rowman \& Littlefield, London 2016), publicado también en Foucault Studies, no 25, october 2018, pp. 299-311; ver p. 306. 
la conferencia «Qu'est-ce que la critique?», es significativamente definida como «el arte de no ser de tal modo gobernado» - «no querer ser gobernado de esa forma»-, «el arte de la inservidumbre voluntaria, de la indocilidad reflexiva ${ }^{84}$. Por su parte, el curso de 1977-1978 ofrece como el primer ejemplo de «contraconducta» en el seno de la pastoral cristiana precisamente el ascetismo: en la medida en que la gubernamentalidad pastoral exige la conducción de conductas a través de la obediencia y la anulación de la voluntad, el ascetismo se convirtió en una práctica de contestación a través de la cual se introducía en los contextos de la vida cristiana «una infinitud», «una incompatibilidad», «un exceso», con respecto a la organización del poder pastoral, «...que hace del ejercicio de sí sobre sí un desafío»" 85 . A través de este problema de la voluntad, Foucault se hace cargo del «sujeto práctico», hasta ahora disuelto en los dispositivos de sujeción, y del que por tanto no podía dar cuenta la analítica del poder. Vemos ahora la posibilidad de una subjetividad que no es sólo el resultado objetivador de las relaciones de saber-poder, sino la subjetividad que toca realidad por sí misma, encontrando en ello el punto de apoyo para la crítica y la resistencia. El idealismo ético de la libertad, de Fichte, llega a ser para Foucault una clave interpretativa, como reconoce en 1979: "la voluntad es lo que fija para el sujeto su propia posición»; «la voluntad es el acto puro del sujeto. Y el sujeto es lo fijado y determinado por un acto de voluntad»; «una voluntad es la actividad misma del sujeto ${ }^{86}$. Pero difícilmente puede verse en esta reinterpretación foucaultiana del problema de la voluntad y del sujeto práctico la asunción de la idea de una libertad originaria, o una vuelta al sujeto moral kantiano, sólo explicables en términos de un desfallecimiento teórico del autor francés ${ }^{87}$.

Cabe, por el contrario, como ha visto R. Schürmann, interpretar la autoconstitución práctica como la propia de un «sujeto anárquico», más que autónomo, que se constituye a sí mismo a través de «micro-intervenciones» dirigidas contra los dispositivos de sujeción. Un sujeto que, de algún modo, habría de hacer suyas las posibilidades que los espacios de libertad existentes

84 "¿Qué es la crítica? (Crítica y Aufklärung)», pp. 8, 9 y 11.

85 Ver Sécurité, territoire, population, pp. 208-211. No parece acertada la interpretación que, sobre este aspecto da D. Lorenzini, quien considera que la diferencia entre la noción de "contra-conducta" y la de "actitud crítica" concierne al hecho de que la primera no toma en consideración el papel de la voluntad en las contra-conductas pastorales ("From CounterConduct to Critical Attitude: Michel Foucault and the Art of Not Being Governed Quite so Much", en: Foucault Studies, no 21, junio 2016, pp. 7-21; ver en especial, pp. 8 y 12).

86 «Entretien inédit avec Michel Foucault 1979», pp. 369-370. En esta última página reconoce expresamente que la idea es «fichteana». La tesis de Fichte es, como se recuerda, que lo que nos pone en contacto con el mundo no es primariamente el intelecto sino la voluntad, y que el sí mismo se funda sólo en la libertad. Ver Fichte, J. G., El destino del hombre, Espasa-Calpe, Madrid 1976, pp. 105-110, 117, etc.

87 A pesar del esfuerzo por analizar con profundidad la problemática, es finalmente el resultado al que se ven conducidos autores solventes como por ejemplo P. Sabot en «Critique, attitude critique, résistance», en: Jolly, E. y Sавот, P. (dirs.), Michel Foucault. À l'épreuve du pouvoir, Presses Universitaires du Septentrion, Lille 2013, pp. 13-26. 
le permiten ${ }^{88}$. Sea como sea, la retracción de los análisis históricos de Foucault al mundo antiguo probablemente le permitió ahondar en la idea de una subjetividad autoconstituida y portadora de una diferencia radical con respecto al mundo pero, al mismo tiempo, no desligada del mundo o sólo perteneciente al mundo nouménico, como la subjetividad kantiana o fichteana. La apuesta de Foucault no es, como la kantiana, pensar una libertad que está «fuera de la provincia del conocimiento ${ }^{89}$, sino más allá, pensar una libertad a la vez externa e interna, libre y ligada. El sujeto práctico en que parece estar pensando Foucault es aquél que, si bien lleva consigo el principio de una crítica con respecto a la realidad presente, convierte ese principio en un modo de existencia y de experiencia, en una actitud. Su acción sobre lo real y sobre sí mismo será, por ello, negativa y afirmativa a un tiempo. Con las palabras con que describe Foucault la «actitud de modernidad»:

Para la actitud de modernidad, el alto valor del presente es indisociable de la obstinación en imaginarlo, en imaginarlo de otro modo distinto y en transformarlo, no destruyéndolo sino captándolo en lo que es. La modernidad baudelairiana es un ejercicio en el que la extrema atención a lo real es confrontada con la práctica de una libertad que a la vez respeta esa realidad y la viola ${ }^{90}$.

Y, dicho con la contundencia con que suele expresarse Foucault en las entrevistas: «Debemos comenzar por reinventar el futuro sumergiéndonos en un presente más creativo»" ${ }^{91}$ "Sugiero algo. Busque lo que es bueno, fuerte, bello en su sociedad y trabaje desde ahí. Empujar hacia afuera (push outward). Crear siempre desde lo que ya tiene. Entonces sabrá qué hacer ${ }^{92}$. Foucault destaca en Le courage de la vérité que el cínico propiamente no elige arbitrariamente su vida sino que sigue una misión: «uno no se auto-instituye cínico» ${ }^{93}$. El cinismo representa el caso límite del sujeto práctico, es verdad, pero probablemente Foucault nos invita a pensar si en todo sujeto práctico no tiene que haber un Diógenes: máxima diferencia con respecto al mundo; máxima mundanidad de la diferencia.

Universidad de Granada

JAVIER DE LA HiguERA

Departamento de Filosofía II

jdelahiguera@ugr.es

[Artículo aprobado para publicación en febrero de 2020]

88 Ver Schürmann, R., «Se constituer soi-même comme sujet anarchique», en: Les Études Philosophiques, $\mathrm{n}^{\circ}$ 4, diciembre 1986, pp. 451-471.

89 Es la interpretación de I. Hacking, quien asimila la libertad foucaultiana a la kantiana. Ver: Historical ontology, Harvard University Press, Cambridge MA 2002, p. 119.

90 «What is Enlightenment?»(1984), Dits et écrits, vol. IV, p. 570.

91 M. Foucault, "Conversation sans complexes avec le philosophe qui analyse les "structures du pouvoir"»(1978), Dits et écrits, vol. III, p. 678.

92 "A Last Interview with French Philosopher Michel Foucault», loc. cit.

93 Le courage de la vérité, p. 269. 